\title{
EDITORIAL
}

\section{LA VIGILANCIA DE SALUD PÚBLICA DURANTE LA PANDEMIA DE GRIPE (H1N1) 2009}

\section{Ildefonso Hernández Aguado}

Dirección General de Salud Pública y Sanidad Exterior. Ministerio de Sanidad y Política Social. Madrid.

Una vez finalizada la fase pandémica de la gripe (H1N1) 2009 se ha iniciado en todos los niveles de decisión, desde el local al internacional, la evaluación de la respuesta dada a este problema de salud. Es por ello especialmente oportuna la publicación de un número monográfico de la Revista Española de Salud Pública recogiendo las diversas experiencias adquiridas en el campo de la vigilancia en salud pública, pilar fundamental de la respuesta.

Cada uno de los artículos aporta piezas clave del trabajo llevado a cabo y nos permite examinar con detalle los espacios de mejora para afinar los planes de preparación y respuesta frente a emergencias y también tejer de forma eficiente una sólida capacidad de detección y vigilancia ante cualquier nueva amenaza de salud pública.

Al aprovechar el trabajo realizado para afianzar nuestros sistemas de vigilancia de salud pública, cabe también mencionar aquellas acciones que han sido destacables. En esa línea hay que subrayar el relevante papel que la vigilancia de la gripe en España jugó en el seguimiento de la pandemia a nivel mundial. Por su sensibilidad en detectar casos, por la adecuada caracterización virológica, por la vigilancia de complicaciones y por la puntualidad y trasparencia pública en difundir los resultados, la calidad de nuestra vigilancia determinó que España jugase un papel activo como interlocutor para la toma de decisiones en las instituciones internacionales de salud pública. Esa influencia fue determinante para algunas de las decisiones clave, como pudo ser la declaración de las fases de la pandemia por la Organización Mundial de la Salud (OMS) o la decisión en el seno de Comité de Seguridad de Salud de la Unión Europea sobre los grupos diana de la vacunación. Se puede afirmar que las contribuciones de España, basadas en una privilegiada información epidemiológica apuntaron en direcciones que posteriormente se han confirmado acertadas. Es el caso de los grupos diana de vacunación, en el que España consiguió que la decisión incluyese grupos más reducidos que las propuestas iniciales de muchos países, que incluían prácticamente a toda la población.

Esta posición relevante de España en la toma de decisiones es consecuencia de un trabajo forjado durante muchos años por servidores públicos comprometidos ya sea en los servicios de salud pública autonómicos, ya sea en los servicios de la Administración General del Estado, en el Ministerio de Sanidad y Política Social o en el Instituto Carlos III. A ellos se suma el trabajo en buena coordinación con buen número de profesionales 
sanitarios en el ámbito clínico y de laboratorio que reflejan en conjunto la pujanza de la salud pública española. Una vitalidad que no debe ser desaprovechada, bien al contrario garantizada mediante la provisión de recursos adecuados.

La vigilancia de salud pública ha mostrado su gran capacidad, queda un atractivo camino que recorrer para hacer de esta acción de salud pública el soporte de unas políticas de salud pública basadas en la consecución de la equidad y la salud. Es un reto de renovación y en ocasiones de reinvención que, dada la fibra de la que están hechos los epidemiólogos, no hay duda de que podremos afrontar con éxito. 